\title{
Hour Squared Times Picomole Per Liter
}

National Cancer Institute

\section{Source}

National Cancer Institute. Hour Squared Times Picomole Per Liter. NCI Thesaurus. Code C106529.

Hours squared times picomoles per liter. 